geologist, botanist, and archæologist. Among other finds it may be mentioned that near Golotizk, on the east coast of the White Sea, be found a great ancient manufactory of flint implements of the stone age, of the purest and highest Scandinavian forms, which previously had been seldom found east of the Baltic, and never on the coast of the Arctic Ocean or the White Sea. The collections will be divided between the State Museums of Russia, Sweden, and Norway, all three countries affording facilities for the conduct of the expedition.

CHINA.-In accordance with the terms of the Chefoo Convention, Her Majesty's minister at Peking, about a year ago, sent to Chung-king, in the Chinese province of Szechuen, which lies at the junction of the River Ho-tow with the Yang-tsze Kiang, Mr. E. Colborne Baber, of her Majesty's Consular Service, who was one of the interpreters attached to the Yünnan mission, and who, before proceeding on that bootless errand, was at considerable pains to qualify himself for scientific exploration. Mr. Baber started last July on an expedition in the western districts of the province. But little was heard of Mr. Baber's doings until the end of the year, except from a private letter in which he described himself as floating down the River Min, among low hills covered with fir and insect wax trees, and in sight of (though at a distance of sixty miles on the south-west) the holy mountain of Omi, on the borders of Thibet. On December 27 the North China Herald, of Sbanghai, published a portion of another letter from $\mathrm{Mr}$. Baber, in which he mentions that, from the point just named, he made north-west and from Ya-chow began to veer south. Passing Ning-yüanfoo he went to Hwa-li-chow ; then turned east and crossed the Yang-tsze into Yünnan, not far from Tung-chwar. Thence through the wildest and ponrest country imaginaible, the great slave-hunting ground from which the Lolos carry off their Chinese bondsmen--a country of shepherds, potatoes, poisonous honey, lonely downs, great snowy mountains, silver mines, and almost incessant rains, Mr. Baber tracked the course of the Upper Yang-tsze to Ping-shan. No European, he says, has ever been in that region before, not even the Jesuit surveyors, and the course of the Yang-tsze, there called the Gold River (Kinsha Kiang), as laid down on their maps, is a bold assumption and altogether incorrect. Mr. Baber adds that "a line, drawn south-west from a mile or two above Pingshan, will indicate its general direction, but it winds about among those grand gorges with the most haughty contempt.for the Jesuits' maps."

MOUNT TONGARIRO.--The celebrated burning mountain of New Zealand, Tongariro, has at last been explored by an Englishman, Mr. P. F. Connelly. The volcano is regarded as $t a p u$, or sacred, by the Maoris, who have hitherto resisted all attempts to explore the mountain on the part of the colonists. The volcano is situated nearly in the centre of North Island, and though only 6,500 feet high, is less accessible than either Mount Edgecumbe or Ruapehu, both of which exceed I0,000 feet in height. Mr. Connelly overcame all resistance, and by the help of some chiefs more friendly than the rest, succeeded in thoroughly exploring the crater, took a number of sketches and photographs of the locality, and determined the positions of the most important peaks.

AFRICAN EXPLORATION.--The King of the Belgians has sent to M. Quatrefages a telegram stating that two other Belgian officers should proceed to Zanzibar within a few days, to supply the places of the unfortunate MM. Crespel and Maes, whose death we announced last week. Telegraphic orders have been sent to the remaining members of the expedition to continue their journey to Tanganyika. The Paris Geographical Society, anxious to acknowledge such a determined policy, have resolved to take steps to accelerate the public subscription instituted on behalf of international African exploration. It has been resolved also to establish a local committee on a very large scale; not less than a hundred persons of distinction will be selected, with power to add to their number.

Paris Geographical Society.--The distribution of prizes will take place not in April, as usual, but at the meeting to inaugurate the Society's hotel, now building. It will be ready in the month of September or October next. The gold medal will be awarded, as already reported, to Mr. Stanley, but another gold medal of the same value will be given to the veteran $M$. Vivien de Saint Martin, the celebrated geographer, for the many valuable works published by him during the last thirty years, and principally "L'Année Géographique."

AMERICAN GEOGRAPHICAI, SOCIETY.-We have received two numbers of the Bullctin of this Society, containing the proceedings of the meetings for the first half of $x 877$. One number is devoted to the admirable summary of geographical work for 1876 , which constituted the address of the President, Chief Justice Daly, and to which we alluded at the time. In the other number (No. 4) the principal paper is on the volcanoes of the U.S. Pacific coast, by Mr. S. F. Emmons.

MAPS Or the SEAT OF WaR.-The Russo-Turkish war has called forth a very large number of maps of the Balkan peninsula. We learn that a Russian gentleman has made a collection of maps of the seat of war, numbering more than 150 , and will exhibit the collection at Paris. The largest number of such maps has been published in Germany, and the most detailed maps appear to be those published in Finland.

Arctic Exploration.-Mr. James Gordon Bennett has petitioned the U.S. Congress to grant the American register to the steamer Pandora for an Arctic expeuition under the command of American naval officers.

\section{SOCIAL ELECTRICAL NERVES}

THE efficient carrying out in a large city of any exterided system of telegraphic communication for police, firc, and social purposes demands an intimate acquaintance with existing systems, so as to insure the establishment of only the most perfect organisation. In an ordinary telegraphic communication between two or more stations a line wire connects the terminal station with the instruments in the circuit, and the distant end of this wire is in connection with the earth, while the other end, after connection through the instrument, passes to one pole of a battery, the other pole of which is also in connection with the earth. Thus the electrical circuit is completed partly by the line wire and partly by the earth wire. Such is an ordinary circuit. At times when telegraphic communication is required only for short distances, as in houses and buildings, a second wire takes the place of the earth circuit. In the auto-kinctic system for the introduction of fire, police, and social telegraphs upon an extended scale an essential feature is the employment of two parallel wires, laid over a city and suburbs, starting from a central station to the various district stations, and from thence ramifying in every direction so as to embrace the most important areas for the purposes required. Each of these two wires has its special duty to perform. One is employed for the purpose of starting the instrument, which may therefore be termed the "starting" wire. The other is used for the transmission of the message, and may be termed the "transmitting" wire. It is by this novel arrangement that the auto-kinetic system enables any number of speaking stations to be placed upon a circuit without possibility of interference. Thus in each district of a 
city-say Glasgow-the head police and fire station in the central district will be in direct communication with the sub-stations in the northern, western, southern, eastern, and St. Rollox districts, and each of these again will be local centres, and command a host of street, fire, and police "call" stations placed at convenient distances along the thoroughfares in their respective districts.

Another distinctive principle of the auto-kinetic system is that which has already been noticed, namely, the "starting" and "transmitting" wire traversing the streets together. If we suppose a number of speaking stations to be required along the route-say $300-$ it is evident that at each point where an instrument is placed the two wires will require to be brought into the instrument-the one to start the instrument when a communication is to be sent, and the other to pick up and automatically transmit that message to the district centre. We have before stated that no instrument is " in circuit" except when speaking, and then only during the time occupied in the transmission of the message. It therefore follows that at each station along the line, while in a state of rest, the electrical continuity of both the "starting" and "transmitting" wire must be maintained independent of the apparatus.

A general outline of the manner of employing these two wires will explain the system.

We will commence first with the modus operandi of the "starting" wire, then with that of the "transmitting" wire, and finally describe the nature of the automatic apparatus by which the novel and important features of the auto-kinetic system are obtained.

Assume for a moment that the apparatus is inclosed in an iron erection somewhat similar to that of a street pillar letter-bux, and that in the inside of this box one portion of the instrument consists of an ordinary electromagnetic coil $\mathrm{C}$, an armature $\mathrm{A}$, and detent $\mathrm{E}$ working on a centre $e$ locking into a small arrangement of wheel-work and barrel $\mathrm{D}$, without any maintaining power ; and that one end of the wire of this electro-magnetic coil is connected permanently with the earth, the other end being attached to a metallic spring S placed in position to form a contact, under certain conditions, with a second spring $\mathrm{S}^{\prime}$. in connection with the "lead in "from the starting wire nearest to the district sub-station. In this position as regards the instrument it is a broken circuit, and of course, therefore, the instrument is out of connection. If now we trace the other "lead in "from the "starting" wire and conceive it to be brought into the pillar-post and carried up to the second spring $s^{\prime}$, and as from this spring a connection exists with the "starting" wire, a continuous metallic circuit is established through the pillar-box, indicated in the illustration by the $\rightarrow$ as far as the passing of "starting" electric currents is concerned from any other instrument along the circuit which may have to travel the wire without affecting the instrument under notice, which

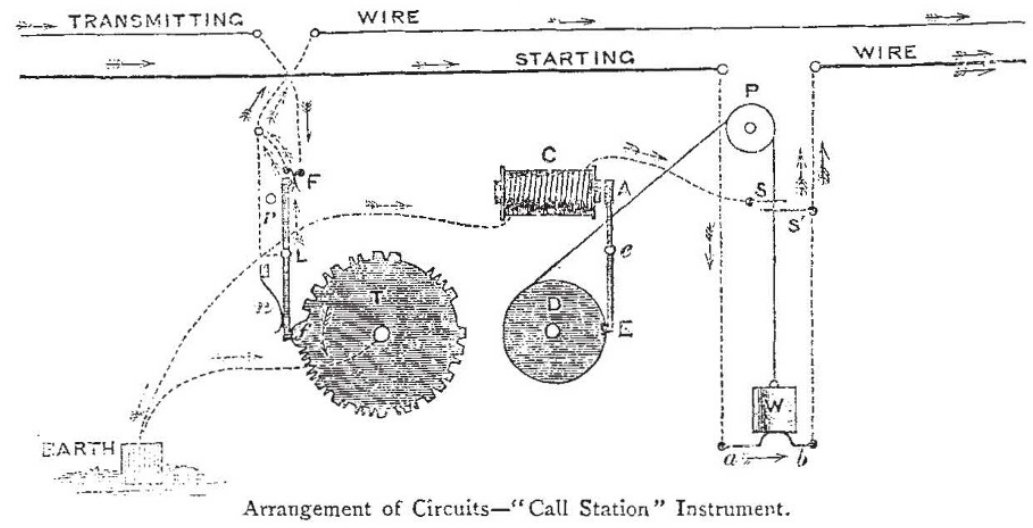

remains electrically out of circuit by reason of the break in continuity at the spring $S$ attached to the coil wire. We will now advance a step further, and assume that the continuity of the "lead in " of the "starting" wire furthest from the district station is only maintained so long as a weight $w$ rests upon the two ends $a$ and $b$. It will therefore be evident that were the weight $\mathrm{w}$ raised, the through continuity at $a b$ maintained by the weight would be destroyed, and until so far raised as to mechanically press the springs $S$ and $S^{\prime}$ together-the coil wire spring and the lead in "starting" wire spring-the through circuit on the starting wire is broken. Now the weight $w$ being raised what follows? The moment that the springs $S$ and $S^{\prime}$ are brought into. contact electrical continuity is established between the district station and this instrument, and the battery current flows from that station along the starting wire, passing all intermediate instruments which are necessarily out of circuit, enters the electro-magnetic coil $\mathrm{C}$, and throws the instrument to earth as a terminal with the district centre, at once cutting off all interference that might arise from other instruments along the line speaking at the same time.

Thus, for the moment that the two springs $S$ and $S^{\prime}$ are in contact, the current has entered the coil $\mathrm{C}$, the armature $\mathrm{A}$ has been attracted, and the detent $\mathrm{E}$ being withdrawn has liberated the drum $D$ which commences to revolve, having been wound up by the elevation of the weight $\mathrm{w}$.
The liberation of the detent, therefore, instantly caid ses the weight $\mathrm{W}$ to descend, and the act of falling separates the two springs $S$ and $S^{\prime}$, the starting wire, as far as this particular instrument is concerned, being thrown off, and the through circuit also remaining broken until the weight has descended and closed the contact by pressure at $a b$.

Before we proceed, let us suppose that during this interval of time between the raising of the weight and its falling, some other instrument or instruments along the line had been called into requisition, what would happen? The weight $w$ at each instrument would have been raised, placing the springs $s$ and $S^{\prime}$ in metallic contact, and the instrument thrown into position ready for speaking; but as no current could pass along the starting wire until continuity had been restored at the $a b$ of the first speaking instrument, which for the moment had become a terminal instrument, no current could enter the coil $\mathrm{C}$ of the second instrument; and as the detent $\mathrm{E}$ could not be released, the weight would remain suspended, until the arrival of the current along the starting wire attracted the armature and released the drum; in due course the second instrument is immediately thrown off the circuit, and succeeded automatically by a third, fourth, or any number along the line in succession, according to their distance from the district centre or battery station. It will therefore be seen that as the battery current always is in readiness to 
follow down the "starting" wire from the central station, were twenty or thirty instruments set in action simultaneously; that nearest the central station will record first, and as, in the act of recording, it becomes a terminal, the remainder will follow in the order of their distance aiong the "starting" wire from the central station. Thus were twenty fires to occur in a district at the same time, and twenty "call" instruments were to be simultaneously put into requisition, the whole twenty would record their several messages without interference at the central station, following one another in successive intervals of time, determined by the automatic falling of the weight on to the circuit poles $a$ and $b$. Now, as this interval of time for each instrument is about three seconds, the whole twenty messages would be automatically recorded in about one minute, or less time than it has taken to read the account of what would take place.

Ve have now traced the action of the "starting" wire, which may be stated to perform its functions mechanically by the act of raising a weight momentarily placing it in circuit with the instrument, which becomes immediately a terminal station; and again by the falling of the weight the instrument is thrown off, and the through circuit along the "starting" wire restored.

We proceed to examine into the action of the second or "transmitting" wire, and explain the process by which, on the starting of the instrument, this picks up automatically the message, and, after transmission, resumes its continuity as a through metallic circuit in relation to the other instruments on the line.

It will be seen, by reference to the diagram, that until the moment that ine instrument is throwri on to the circuit of the "starting" wire by the raising of the weight, w, the through continuity of the "transmitting" wire is maintained as indicated by the arrows $\longrightarrow$, and that the instrument is completely cut out of the circuit. Now the act of starting the drum, D, by the action of the "starting" current, sets in motion, by the force of the dicscending weight, the small train of wheels before mentioned, the use of which is to give motion to the disc, T, bearing the code message upon its circumference. This disc makes exactly one revolution in the interval of time occupied by the falling of the weight, the distance between the springs, $\mathrm{SS}^{\prime}$, and the circuit contact, $a b$, upon the restoration of which, the drum, D, is again locked by the detent, $E$, and the message disc has assumed its normal position.

We will now trace the action of this message disc. The through continuity of the transmitting wire, when the disc is at rest, is maintained by the pressure of the lever, L, upon the two circuit springs, F. This pressure is exerted so long as the disc is in position by means of the insulated stud, $f$, upon which the lower end of the lever, $\mathrm{L}$, rests. The moment, however, that the disc, T, revolves, the lever, $\mathrm{L}$, falls back upon the pin, $r$, the contact between the springs, $F$, is broken, and the transmitting wire is thrown to earth, through the disc. As the end of the lever, L, comes into metallic contact with the "make" and "break" prominences upon its circumference, currents flow to the central station along the circuit in the direction indicated by the dotted arrows. Now as these currents are passed in groups to represent letters and words, a code message, or any code message out of a given number, may be automatically printed at the receiving instrument at the central station. In the example given, the currents passed are the Morse signals, indicating the position of the calling station, namely, MAIN ST., GORBALS, which would at once inform the central station of the exact locality of the fire. The weight once more at rest, the transmitting wire is no longer to earth at that call station, but is again thrown into circuit by the contact of the springs, $F$.

From the explanations given, several very important resulis have been established. Every instrument while transmitting a code message is for the moment made a terminal station, all other instruments on the same circuit being thrown off so as to avoid all possibility of interference. At no time is any greater resistance thrown into the circuit than that of the single instrument employed to transmit the code message. Again, only a very small amount of battery power at the central station is required, only one instrument being in action at the same time. Whatever number of instruments on a circuit may be called into requisition at the same time, they will all automatically record their messages one after the other in succession, commencing with that nearest to the battery station, and be all automatically started and brought to rest, without any mechanical complication of parts or delicate electrical adjustments. Such results have never before been obtained and at once place the auto-kinetic system in advance of every other.

A general description of the apparatus, as placed in the hands of the public will now be comparatively easy to understand, and the stability and simplicity of its construction at once recognised.

A messenger presenting himself before any one of the street pillar "call stations" will, on opening the iron door, find a dial plate on which some eighteen or twenty printed sentences are enamelled in bold characters; first, the name of the street indicating the position of the "call station," as in the example given-" Main street, Gorbals" -and following in rotation others, such as "warehouse on fire," "dwelling-house on fire," "mill on tire," "theatre on fire," "send more assistance," "fire got under," "police constable needed," \&c. Opposite to each message will be found a substantial knob or handle, something like the "draw-stop" of an organ. The pullir:gr oit of tire handle opposite the particular code message required causes the instrument to transmit that message to the central station, where it is printed upon a self-recording Morse receiver; and intimation is given to the inspector on duty of the arrival of a "call" by the ringing of a bell during the time the message is being printed. The description previously given of the interior construction of the instrument will readily explain that the pulling out of the handle simply raises the weight, and that the final transmission of the message is indicated by the return of the handle to its normal position upon the descent of the weight. As any number of code message discs may be mounted upon the same shaft, and as each disc would have its special make and break lever acting upon the circuit springs, $\mathrm{F}$, there is little additional complication in the internal arrangement from a plurality of code signals being introduced, the working parts being mostly common to either one or twenty discs. The advantages above described are not the only features of importance in connection with the auto-kinetic system.

A corporation carrying out such a system as described for street police,"and fire "call stations," may derive a considerable annual revenue from introducing special "private fire call" instruments into all the large mills, warehouses, works, and more important private dwellings at a small annual charge to the respective owners. As the number of such "private call" stations introduced upon the circuit is practically without limit, irrespective of the money return to a corporation in a commercial view, the great security to property against any very serious loss by fire is a matter of vast importance. It is well known that the annual losses by fire amount to enormous sums, and often thousands of pounds may be lost by a few minutes' delay in giving early intimation of the outbreak to the brigade.

The auto-kinetic system of using the two wires whereby only one speaking instrument can be in circuit at a time, renders them likewise peculiarly adapted for the employment of the telephone in introducing a social system of communication between offices and works, or for the legal profession between the courts and their various 
offices, as all messages of the most private nature can be sent without publicity, an advantage possessed by no other system.

It is unnecessary to point out any other of the many practical applications to which this auto-kinetic system may be applied. It is a system that must shortly extend its social metallic nerves to all the large centres of commerce and manufacture in this kingdom, and its various applications will then become more fully developed and known.

\section{THE RAIN-TREE OF MOYOBAMBA}

SOME little while since a paragraph went the round of $S$ the papers, describing, on the authority of the United States Consul in the province of Loreto, a tree existing in the forests near Moyobamba, in Northern Peru.

According to the Madras Times and Overland Mail of December 15,1877 , "The tree is stated to absorb and condense the humidity of the atmosphere with astonishing energy, and it is said that the water may frequently be seen to ooze from the trunk, and fall in rain from its branches in such quantity that the ground beneath is converted into a perfect swamp. The tree is said to possess this property in the highest degree during the summer season principally, when the rivers are low and water is scarce, and the Consul therefore suggests that the tree should be planted in the arid regions of Peru, for the benefit of the farmers there."

As always happens in cases of this kind, there have not been wanting those who have taken this singular story quite scriously, and the India Office has applied to the Royal Gardens, Kew, on behalf of the Agri-Horticultural Society of Madras for information about the tree. It may be interesting to some of the readers of NATURE, and it will cortainiy saye futture correspondence, if I explain once for all what I have been able to ascertain as to the origin of the fable and the amount of truth which it contains.

Poppig's "Reise in Chile und Peru" (2 vols., 1835), which contains much useful botanical information, apparently makes no reference to the subject.

I am indebted to Dr. Francis Darwin for pointing out to me a very similar account which appears in the Botanische Zitumer, January 21 , IS76, pp. 35, 36, in which Prof. Ernst, of the University of Caracas, records his observations upon a tree of Pithecolobium (Calliandra) Saman, Benth.

"In the month of April the young leaves are still delicate and transparent. During the whole day a fine spray of rain is to be noticed under the tree, even in the driest air, so that the strongly-tinted iron-clay soil is distinctly moist. The phenomenon diminishes with the development of the leaves, and ceases when they are fully grown."

I found that the specimens of this tree in the Kew Herbarium brought its range close to Moyobamba, as they included some gathered by the traveller Spruce, near the neighbouring town of Tarapoto. It appeared probable, therefore, that the Tamia-caspi-the name given in one variant of the story-was Pithecolobium Saman, though the cause of the rain was more mysterious than ever. Being vouched for by so competent an observer as Prof. Ernst, its occurrence could not well be denied, while on the other hand, the Pithecolobium being a wellknown cultivated tree in the West Indian Islands, it was quite clear that if the "raining" from its foliage were a normal occurrence, it would long ago have been put on record.

Mr. Spruce has, however, obligingly supplied me from the astonishing stores of information which he possesses with the true history of the whole matter, and he has also been so good as to allow me to communicate to the readers of NATURE the substance of what he has told me.

"The Tamia-caspi, or rain tree of the Eastern Peruvian Andes, is not a myth, but a fact, although not exactly in the way popular rumour has lately presented it. I did not know there was any doubt as to the true origin of the 'rain.' I first witnessed the phenomenon in September, I 855, when residing at Tarapoto (lat. $6 \frac{1}{2}^{\circ} \mathrm{S}$., long. $76^{\circ} 20^{\prime}$, W.), a town or large village a few days eastward of Moyobamba, and little more than $I, \infty 00$ feet above the sealevel. I had gone one morning at daybreak, with two assistants, into the adjacent wooded hills to botanise. .... A little after seven o'clock, we came under a lowish spreading tree, from which with a perfectly clear sky overhead a smart rain was falling. A glance upwards showed a multitude of cicadas sucking the juices of the tender young branches and leaves, and squirting forth slender streams of limpid fluid. We had barely time to note this when we were assailed by swarms of large black ants, which bit and stung fiercely, and obliged us to beat a retreat, my companions calling out as they ran "TamiaCaspi! Tamia-Caspi!' When we had shaken off our assailants, I ventured to approach the spot so near as to make out that the ants were greedily licking up the fluid as it fell. . . .

"My two Peruvians were already familiar with the phenomenon, and they knew very well that almost any tree, when in a state to afford food to the nearly omnivorous cicada, might become (pro tem.) a Tamia-caspi, or rain-tree. This particular tree was evidently, from its foliage, an Acacia, but as I never saw it in flower or fruit, I cannot say of what species. I came on cicadas, similarly occupied, a few times afterwards, and on trees of very different kinds, but never without the pugnacious ants on the ground beneath. Among the trees on which I have seen cicadas feed, is one closely allied to the acacias, the beautiful Pithecolobinm Saman. The young branches are very succulent, and they bear elegant bipinnate leaves. ... The pods are greedily eaten by deer and catlle. Ancther leguminous tree visited by cicadas is Andira incrnis, and there are many more of the same and other families which I cannot specify. Perhaps they avoid only such as have poisonous or strongly resinous juices; and those which are permanently tenanted by ferocious ants such as all Polygonece, the leguminous Platymiscium, and a few others. ... These ants rarely leave the tree which affords them food and shelter, and they jealonsly repel all intruders, the slightest scratch on the smooth bark sufincing to call their sentinels to the spot. They are quite distinct from the robust maratiding ants that drink the cicadas' ejectamenta.

"I have no doubt you have above the true explanation of the Tamia-caspi, or rain-tree. As to the drip from a tree causing a little bog to form underneath and around it, that is a very common circumstance in various parts of the Amazon Valley, in flats and hollows, wherever there is a thin covering of humus, or a non-absorbent sub-soil, and the crown of foliage is so dense as to greatly impede evaporation beneath it. On such sites the Achuál palm (Mauritia flcxuosa) common enough between Moyobamba and Tarapoto, as well as on the savannabs of the Orinoco, and in subriparial forests of the Amazons--affords a striking example of this property, as has already been remarked by Gumilla, Velasco, Humboldt, and others. Finally, although I never heard the name Tamia-Caspi applied to any particular kind of tree, during a residence of two years in the region where it is now said to be a speciality, it is quite possible that in the space of twentyone years that have elapsed since I left Eastern Peru, that name may have been given to some tree with a greater drip than ordinary; but . I expect the cicada will still be found responsible for " the moisture pouring from the leaves and branches in an abundant shower'-the same as it was in my time."

Mr. Spruce's notes are so precise and careful that there is little difficulty in accepting his explanation of the raintree. It is, however, hard to understand the omission of all insect agency in the equally careful account given by 